\title{
Análise estratigráfica das seqüências neoproterozóicas da Bacia do São Francisco
}

\author{
Mariela Martins $^{1}$ \& Valesca Brasil Lemos ${ }^{2}$
}

\begin{abstract}
Resumo Os princípios da estratigrafia de seqüência foram utilizados para realizar uma análise estratigráfica nas seqüências sedimentares neoproterózoicas da Bacia do São Francisco (Brasil Central). Foram reconhecidos três períodos de deposição separados por discordâncias na Megasseqüência São Francisco: (1) Seqüências 1 e 2, seqüência glaciogênica de Idade Criogeniana seguida de uma rampa carbonática distalmente escarpada desenvolvida sobre condições tectônicas estáveis, (2) Seqüência 3, rampas homoclinais estaqueadas com sedimentação mista carbonática-siliciclástica de idade Criogeniana Superior, depositada sobre uma progressiva influência dos esforços compressivos do Ciclo Brasiliano, (3) Seqüência 4, plataforma rasa de idade Ediacarana Inferior dominada por sedimentação siliciclástica de natureza molássica, produto da erosão dos cinturões de empurrão em elevação nas áreas adjacentes. Cada uma das seqüências carbonáticas apresenta uma assinatura isotópica $\delta^{13} \mathrm{C}$ distinta. A superposição com a curva de variação isotópica global do carbono permite o reconhecimento de um hiato deposicional entre as megasseqüências Paranoá e São Francisco, e sugere que a deposição dos diamictitos (Formação Jequitaí) teve lugar mais provavelmente ao redor de 800 Ma. Isto limita a deposição da Megasseqüência São Francisco ao intervalo entre 800 e 600 Ma (idade reconhecida do limite superior da Orogenia Brasiliana). Um hiato deposicional de expressão menor (700-680 Ma) foi também identificado separando as seqüências 2 e 3 . As análises isotópicas sugerem que a partir desse momento, condições ambientais mais restritas estabeleceram-se na bacia, provavelmente associadas com um evento global de primeira ordem, que prevaleceu durante toda a deposição da Seqüência 3.
\end{abstract}

Palavras-chave: estratigrafia, seqüências, Neoproterozóico, isótopos.

\begin{abstract}
Stratigraphical Analysis of the Neoproterozoic Sedimentary Sequences of the São Francisco Basin. A stratigraphical analysis was performed under the principles of Sequence Stratigraphy on the neoproterozoic sedimentary sequences of the São Francisco Basin (Central Brazil). Three periods of deposition separated by unconformities were recognized in the São Francisco Megasequence: (1) Sequences 1 and 2, a cryogenian glaciogenic sequence, followed by a distal scarp carbonate ramp, developed during stable conditions, (2) Sequence 3, a Upper Cryogenian stack homoclinal ramps with mixed carbonate-siliciclastic sedimentation, deposited under a progressive influence of compressional stresses of the Brasiliano Cycle, (3) Sequence 4, a Lower Ediacaran shallow platform dominated by siliciclastic sedimentation of molassic nature, the erosion product of the nearby uplifted thrust sheets. Each of the carbonate-bearing sequences presents a distinct $\delta^{13} \mathrm{C}$ isotopic signature. The superposition to the global curve for carbon isotopic variation allowed the recognition of a major depositional hiatus between the Paranoá and São Francisco Megasequences, and suggested that the glacial diamictite deposition (Jequitaí Formation) took place most probably around $800 \mathrm{Ma}$. This constrains the São Francisco Megasequence deposition to the interval between 800 and $600 \mathrm{Ma}$ (the known ages of the Brasiliano Orogeny defines the upper limit). A minor depositional hiatus (700-680 Ma) was also identified separating sequences 2 and 3. Isotopic analyses suggest that from then on, more restricted environmental conditions were established in the basin, probably associated with a first order global event, which prevailed throughout deposition of the Sequence 3.
\end{abstract}

Keywords: stratigraphy, sequence, Neoproterozoic, isotopes.

INTRODUÇÃ̃ O presente trabalho enfoca os processos deposicionais, sistemas e unidades estratigráficas do Neoproterozóico da Bacia do São Francisco. Nessa bacia, particularmente na área conhecida como Faixa de Dobramentos Brasília, ocorrem excelentes afloramentos de quase todo o seu registro sedimentar, do Mesoproterozóico ao Neoproterozóico. Um espectro muito amplo de ambientes sedimentares, principal- mente plataformas mistas, carbonático-siliciclásticas, acha-se aí representado e presta-se aos objetivos propostos a seguir.

Na Faixa de Dobramentos Brasília, a tectônica compressional do Ciclo Brasiliano trouxe à superfície o registro sedimentar da bacia referente ao intervalo Mesoproterozóico/Neoproterozóico. A tectônica, nesse aspecto, foi um agente facilitador para o geólogo, mas 
os dobramentos dificultaram a interpretação estratigráfica, gerando um grande número de colunas estratigráficas, onde muitas das unidades foram delimitadas com base em critérios geotectônicos e/ou geocronológicos, associados a uma visão estratigráfica clássica de bolo de camadas. Assim, além das dificuldades impostas pela grande extensão da bacia, ao se tentar compreender a história das coberturas sedimentares dela como um todo, o intérprete se depara com um emaranhado de nomes, que não se ajustam e que pouco acrescentam à história deposicional da mesma.

Nenhuma das análises estratigráficas já propostas para o intervalo Neoproterozóico nessa área utilizou a estratigrafia de seqüências como ferramenta para individualização de unidades estratigráficas e compreensão dos seus respectivos processos deposicionais. A revisão estratigráfica realizada por Dominguez (1993) para as coberturas sedimentares proterozóicas do Cráton do São Francisco foi a primeira abordagem mais regional suportada por esse enfoque, centralizada, porém, principalmente nos dados relativos à Chapada Diamantina.

Aqui se apresenta, portanto, o estudo detalhado desse intervalo, utilizando a Estratigrafia de Seqüências, com dados sistematicamente obtidos em inúmeras viagens ao campo, cobrindo as áreas sedimentares neoproterozóicas da Faixa de Dobramentos Brasília e parte das coberturas neoproterozóicas adjacentes ao Cráton do São Francisco. Foram utilizadas informações de subsuperfície (secções sísmicas e poços profundos perfurados pela PETROBRAS e CPRM e localizados na porção central da bacia) das áreas cratônicas não deformadas e afloramentos em Goiás e Minas Gerais.
CONTEXTO GEOLÓGICO O intervalo Meso/Neoproterozóico representa, de forma genérica, uma sedimentação mista carbonática/siliciclástica, em ambiente inicialmente plataformal dominado por ondas de tempestades e marés, e que, a partir do Neoproterozóico, passa a se caracterizar como uma rampa muito suave. Os depósitos neoproterozóicos foram divididos em seqüências deposicionais com base no reconhecimento de discordâncias, em variações bruscas no empilhamento vertical das fácies e em contrastes fortes nos perfis isotópicos do $\delta^{13} \mathrm{C}$ (Martins 1999).

ANÁLISE SISMOESTRATIGRÁFICA A partir da análise sismoestratigráfica, foram reconhecidas duas megasseqüências, separadas por uma discordância de expressão regional, que coincide com o limite já estabelecido entre o Supergrupo São Francisco e o Grupo Paranoá. Representam dois momentos distintos de preenchimento da bacia, com estilos próprios e provavelmente sobre condições tectônicas diferentes. Informalmente serão denominadas de megasseqüências Paranoá (inferior) e São Francisco (superior) (Fig. 1).

A Megasseqüência Paranoá, que não faz parte do escopo deste trabalho, se caracteriza por apresentar uma sismofácies com raras reflexões internas, típica de seqüências mais arenosas. Em direção à borda oeste da bacia, um conjunto de reflexões plano paralelas aparece no topo dessa seqüência, provavelmente relacionadas à presença de depósitos carbonáticos, dentro do contexto de plataforma mista. Entretanto, face ao processo de deformação compressional de idade Brasiliana, que afetou epidermicamente toda a borda oeste, é difícil correlacionar os eventos deposicionais observados em

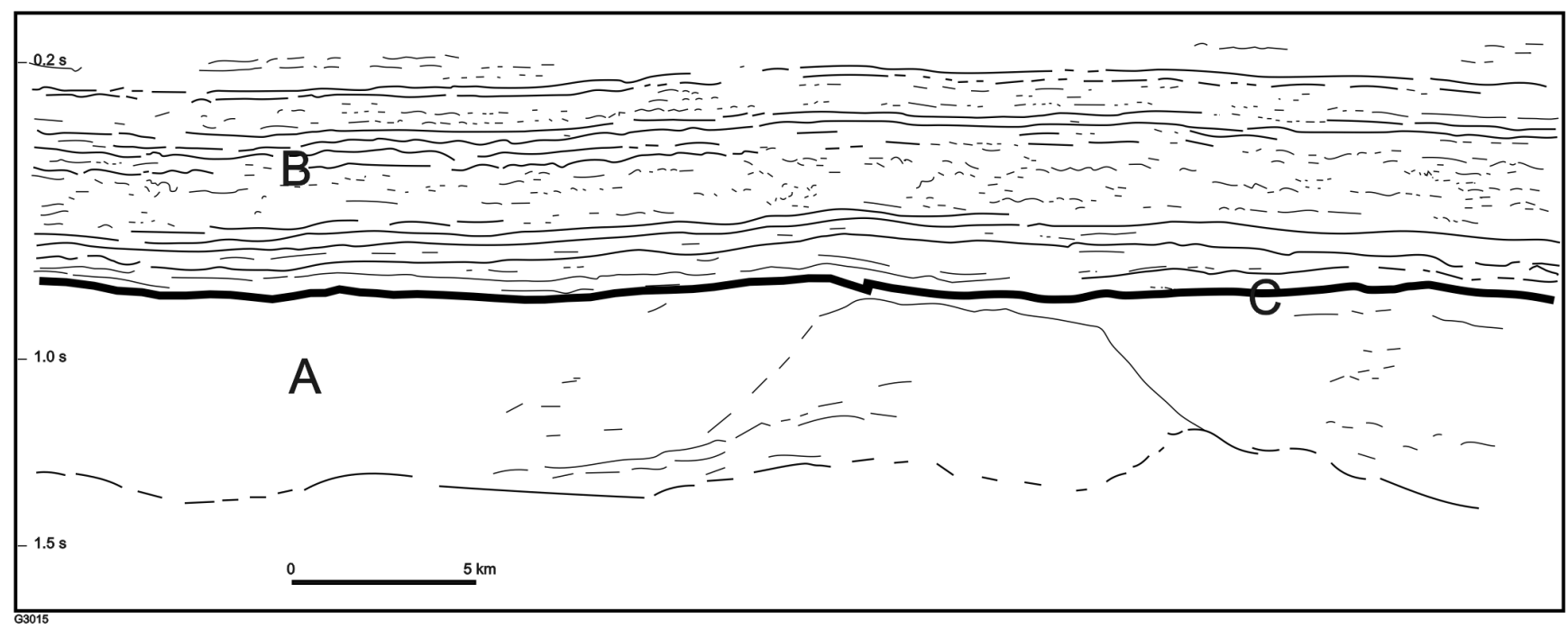

Figura 1 - Desenho esquemático sobre linha sísmica da Bacia do São Francisco, mostrando duas sismofácies distintas: (A) Megasseqüência Paranoá com raras reflexões internas, e que em direção a borda oeste apresenta um conjunto de reflexões paralelas no topo e (B) Megasseqüência São Francisco com três conjuntos de reflexões internas de alta freqüência, intercalados às áreas de caráter caótico, correspondentes aos ciclos deposicionais carbonáticos separadas por (C) uma superficie de forte amplitude (discordância). 
superfície com seu correspondente sísmico.

Por outro lado, a Megasseqüência São Francisco exibe três conjuntos de reflexões internas, de alta freqüência, intercalados às áreas de caráter caótico ou com variações laterais de amplitude, que correspondem aos ciclos deposicionais carbonáticos desse intervalo (Fig. 1) e que foram amplamente amostrados pelos poços.

A discordância, que separa essas seqüências, aparece sismicamente como uma superfície de forte amplitude, contra a qual são observados recobrimentos em onlap dos carbonatos basais da Megasseqüência São Francisco (Fig. 1).

ANÁLISE ISOTÓPICA DO $\boldsymbol{\delta}^{\mathbf{1 3}} \mathbf{C}$ Os trabalhos mais sistemáticos envolvendo a estratigrafia isotópica, ao longo de seções completas no Cráton do São Francisco, concentram-se principalmente nos carbonatos dos grupos Bambuí e Una (Martins 1999). A maior parte dos valores de $\delta^{13} \mathrm{C}$ obtidos nos perfis isotópicos segue uma tendência geral, independente do conteúdo mine- ralógico, localização e preservação da fábrica original da amostra. Isto sugere que esses registros representam um sinal isotópico primário, com condições de correlação em escala regional.

A figura 2 exibe a comparação dos perfis de $\delta^{13} \mathrm{C}$ obtidos por vários autores, em diferentes localizações no cráton, correlacionando anomalias similares. Da base para o topo, os valores $\delta^{13} \mathrm{C}$ foram assim agrupados: (a) carbonatos da Megasseqüência Paranoá com valores em torno de $0 \%$, (b) carbonatos menos enriquecidos em $\delta^{13} \mathrm{C}$ (valores inferiores a 5\%, área cinza hachurada) da Megasseqüência São Francisco (Fm. Sete Lagoas) e (c) carbonatos mais enriquecidos em $\delta^{13} \mathrm{C}$ (valores superiores a 5\%) do topo da Megasseqüência São Francisco.

Observa-se que, valores acentuadamente mais negativos (em torno de $-5,0 \%$ ) ocorrem na base dos grupos Bambuí/Una ou Megasseqüência São Francisco (base da área hachurada da Fig. 2), associados às fácies dolomíticas avermelhadas e imediatamente após sedimentos glaciogênicos. Essas correlações permitem

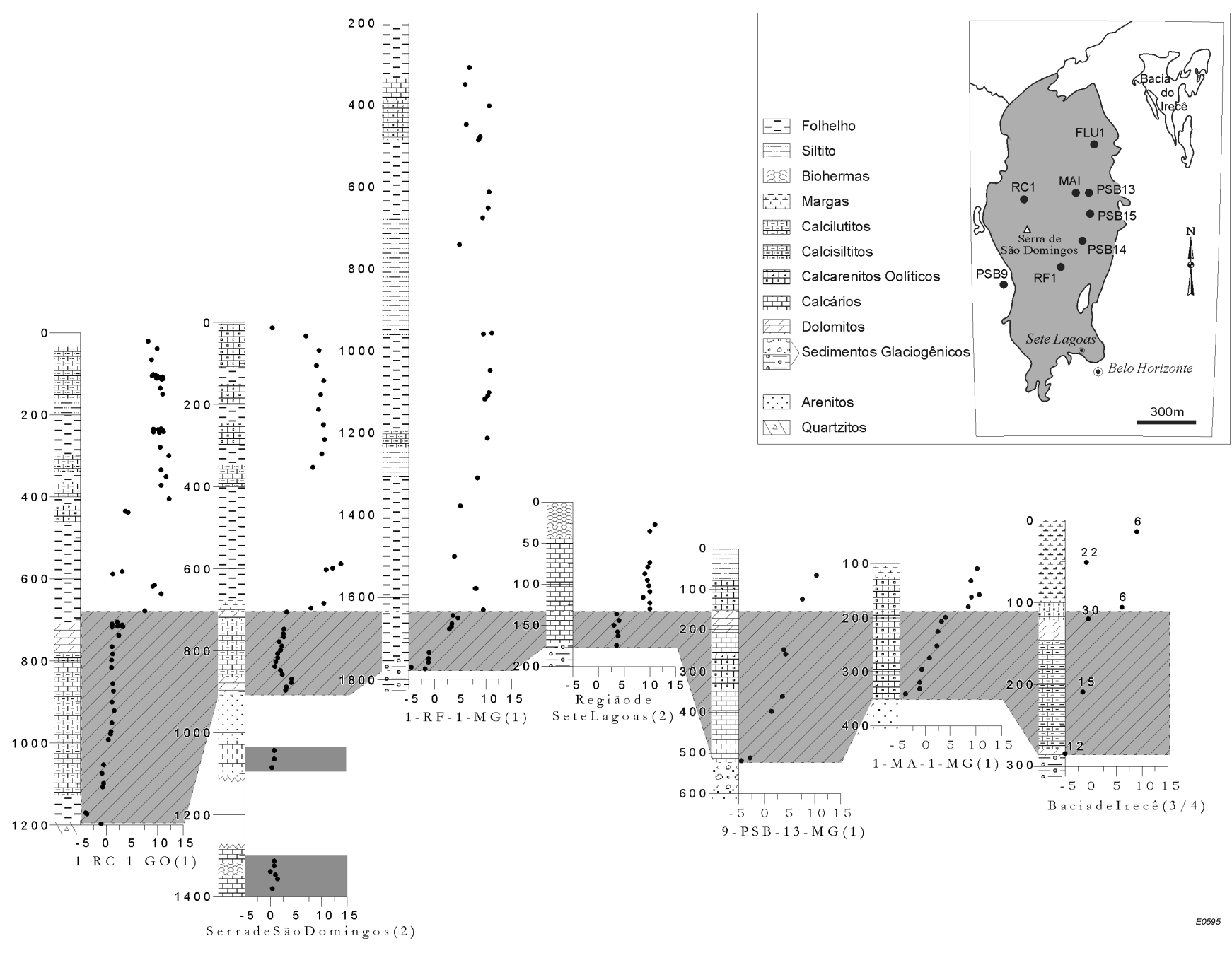

Figura 2 - Seção comparativa dos perfis $\delta^{13} C$ modificado de Martins (1999) com datum posicionado na quebra isotópica que marca a passagem dos carbonatos menos enriquecidos em $\delta^{13} \mathrm{C}$ (valores inferiores a 5\%o, área hachurada) para os mais enriquecidos (valores superiores a 5\%o) no Grupo Bambuí. Os carbonatos do Grupo Paranoá amostrados apenas na Serra de São Domingos (em cinza claro). Para a bacia de Irecê foram plotados os valores médios (número de amostras indicados no perfil). Escala vertical em metros. 
caracterizar essa anomalia negativa como um evento isotópico negativo de $\delta^{13} \mathrm{C}$ de expressão regional. Anomalias negativas de $\delta^{13} \mathrm{C}$ são características de carbonatos depositados logo após períodos glaciais, refletindo mudanças na composição da água do mar decorrentes da deglaciação no Proterozóico Superior (Kaufman et al. 1998, entre outros).

A partir dessa anomalia, os carbonatos da área hachurada apresentam uma assinatura de $\delta^{13} \mathrm{C}$ normalmente positiva (entre 0,0 e 5,0\%o), sucedida por um salto isotópico para valores em torno de 10\%. Nota-se ainda, que o comportamento isotópico do intervalo com valores de $\delta^{13} \mathrm{C}$ entre 0,0 e 5,0\%o varia na direção nordeste, isto é, nessa direção o enriquecimento em $\delta^{13} \mathrm{C}$ é gradual até atingir valores máximos próximos de 5,0\%o (vide perfis 1-RF-1-MG, 9-PSB-13-MG e 1-MA-1-MG na Fig. 2). Para oeste existe uma constância de razões isotópicas em torno de 0,0\%o (perfis 1-RC-1-GO, Serra de São Domingos e região de Sete Lagoas na Fig. 2).

Qual o significado desse salto isotópico durante a sedimentação dos carbonatos da Megasseqüência São Francisco? Levando em conta que não existe nenhuma grande lacuna no registro sedimentar desses perfis, o salto positivo de $5,0 \%$ em $\delta^{13} \mathrm{C}$ representaria um evento isotópico de escala regional, característico da porção superior dos carbonatos da seqüência inferior da Megasseqüência São Francisco (leia-se Formação Sete Lagoas). A sua ocorrência de forma abrupta em todos os perfis, após um conjunto de valores entre 0,0 e 5,0\%o, é mais um indicativo de tratar-se de um marco cronoestratigráfico, uma discordância, possivelmente associada a um evento global de $1^{\text {a }}$ ou $2^{\text {a }}$ ordem. O mapa de localização dos perfis (Fig. 2) ilustra sua ampla ocorrência na bacia.

A descrição das fácies carbonáticas associadas a essa discordância isotópica inclui feições de dissolução, teepees, gretas de contração, dolomitos, brusca mudança faciológica, além de discretas variações nos mergulhos regionais (poços 1-RF-1-MG, 1-RC-1-GO, 9-PSB-13-MG).

Valores extremamente altos de $\delta^{13} \mathrm{C}$ podem ser explicados com base no mecanismo de enriquecimento isotópico por evaporação de salmouras ou por processos secundários. Uma coluna de água altamente estratificada resulta na acumulação de carbono isotopicamente depletado como matéria orgânica no fundo dos oceanos, enquanto as águas rasas tornam-se progressivamente enriquecidas em ${ }^{13} \mathrm{C}$. A evaporação de uma massa de água rasa já enriquecida em ${ }^{13} \mathrm{C}$, poderia resultar em valores muito positivos de $\delta^{13} \mathrm{C}$ (Iyer et al.1995 e Li \& Ku 1997).

Portanto, essa variação positiva no perfil de $\delta^{13} \mathrm{C}$ reflete uma mudança no padrão de circulação oceânica, típico de oceanos ventilados para uma situação de mares estratificados, com grande potencial de preservação de matéria orgânica.

Essa hipótese encontra apoio no comportamento das curvas de $\delta^{18} \mathrm{O}$ da bacia para esse mesmo intervalo conforme discutido por Martins (1999). Embora mais afetados por fatores externos que os perfis isotó- picos de carbono, os resultados de $\delta^{18} \mathrm{O}$ apresentam um enriquecimento progressivo em ${ }^{18} \mathrm{O}$ em direção ao topo da seqüência. Esse enriquecimento pode ser interpretado como resultado de uma taxa de evaporação mais alta que a precipitação, provavelmente em condições ambientais de águas mais rasas e restritas. Essas condições concordam com o quadro paleogeográfico proposto para a seqüência carbonática inferior da Megasseqüência São Francisco (Formação Sete Lagoas), de rampa distalmente escarpada e estaqueada, com as áreas rasas prolíferas em microbialitos.

Outro mecanismo possível para explicar o enriquecimento em $\delta^{13} \mathrm{C}$ nos carbonatos do topo da $\mathrm{Me}$ gasseqüência São Francisco seria pelo processo de metanogênese (matéria orgânica ${ }^{\circledR}{ }^{12} \mathrm{CH}_{4}+{ }^{13} \mathrm{CO}_{2}$ ). Se na diagênese esse ${ }^{13} \mathrm{CO}_{2}$ for incorporado aos carbonatos, esses serão enriquecidos em $\delta^{13} \mathrm{C}$, com valores superiores a 5\%o. Esse mecanismo é controlado pela atividade microbial, sendo mais efetivo nos processos de fermentação (Irwin 1980).

$\mathrm{O}$ efeito conjunto desses dois mecanismos (aumento da evaporação e produtividade orgânica) resulta numa elevação tanto das razões isotópicas $\delta^{13} \mathrm{C}$, quanto das razões $\delta^{18} \mathrm{O}$ ( $\left.\mathrm{Li} \& \mathrm{Ku} 1997\right)$.

$\mathrm{O}$ registro de $\delta^{13} \mathrm{C}$ mais completo na bacia é o da Serra de São Domingos, por incluir também os carbonatos mais antigos pertencentes à Megasseqüência ou Grupo Paranoá (Fig. 2). Os valores de $\delta^{13} \mathrm{C}$ desses carbonatos aparecem depletados em torno de 1,5\%o com relação aos carbonatos da base da Megasseqüência São Francisco, sugerindo um aumento nas condições de restrição da bacia na passagem Paranoá-São Francisco.

Em resumo, a partir da deposição dos carbonatos da Megasseqüência Paranoá observa-se uma crescente restrição nas condições deposicionais da bacia, acentuada durante a sedimentação São Francisco. Uma anomalia negativa em $\delta^{13} \mathrm{C}$, associada a um evento glacial, marca o início da deposição dos carbonatos da Megasseqüência São Francisco, formando um horizonte isotópico contínuo, que separa os dois grupos. A distribuição regional dos perfis isotópicos da Fig. 2 mostra, durante a deposição da primeira seqüência carbonática da Megasseqüência São Francisco (Formação Sete Lagoas), uma área progressivamente mais confinada na direção nordeste (valores crescentes de $\delta^{13} \mathrm{C}$ ), ao contrário da situação de aparente equilíbrio nos valores de $\delta^{13} \mathrm{C}$ a oeste na bacia (oceano mais ventilado). A figura 3 apresenta uma recomposição paleogeográfica hipotética, para esse momento deposicional da Megasseqüência São Francisco, baseada nesse comportamento isotópico. Esse padrão é subitamente modificado, em algum momento, ao final da deposição desses carbonatos, quando novas condições paleogeográficas se estabeleceram na bacia, provavelmente associadas a algum evento global de $1^{\text {a }}$ ordem. Essa nova condição paleoambiental deverá permanecer até o final da deposição dos carbonatos da Megasseqüência São Francisco.

As variações isotópicas, que aparecem em escala mais localizada, foram interpretadas como possíveis efeitos de processos diagenéticos, como por exemplo, a 


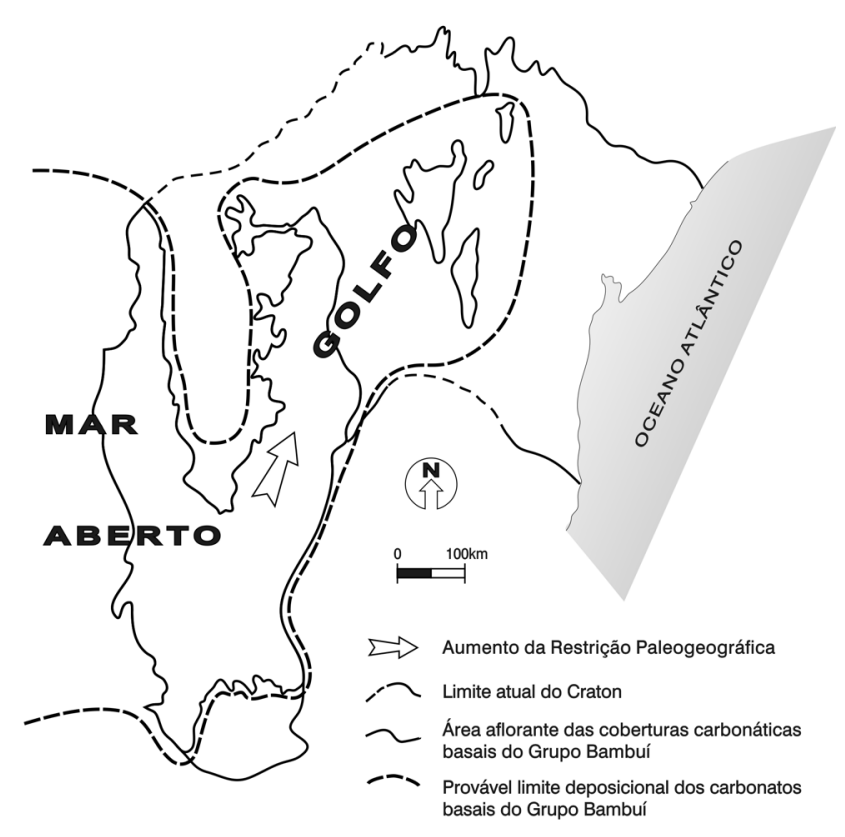

Figura 3 - Recomposição paleogeográfica hipotética para o início da deposição carbonática da Megasseqüência São Francisco baseada na interpretação dados isotópicos de $\delta^{13} \mathrm{C}$ da seqüência carbonática inferior, litologicamente Formação Sete Lagoas (área hachurada da figura 1). O enriquecimento nos valores de $\delta^{13} C$ para nordeste indica aumento nas condições de restrição paleogeográfica, numa situação tipo golfo, no mesmo tempo deposicional.

dolomitização.

Implicações globais A construção da curva isotópica global para o $\delta^{13} \mathrm{C}$ no Proterozóico constitui, ainda, um trabalho em andamento, requerendo um refinamento cronológico e uma interpretação mais consistente de seu registro, tanto do ponto de vista das causas, como das suas conseqüências na biosfera. Recentemente, a compilação dos dados isotópicos e das idades já publicadas revelou que, do Meso ao Neoproterozóico, o registro isotópico para o carbono pode ser dividido em três intervalos distintos (Kah et al. 1998; Fig. 4):

(1) De 1600 a $1300 \mathrm{Ma}$, um intervalo de aquiescência isotópica $\left(\delta^{13} \mathrm{C}=0,0 \pm 1,0 \%\right)$, sugerindo uma estabilidade nos reservatórios de oxidação e redução da Terra.

(2) A partir de $1300 \mathrm{Ma}$, uma nova linha base se estabelece, com razões isotópicas moderadamente mais elevadas $\left(\delta^{13} \mathrm{C}=3,5 \pm 1,0 \%\right)$, pontuada por muitas excursões negativas breves.

(3) Finalmente, entre 800 e $700 \mathrm{Ma}$, o registro isotópico de carbono torna-se extremamente positivo (valores excedem 5,0\%o) com excursões muito negativas.

Conforme discutido, os registros isotópicos para o $\delta^{13} \mathrm{C}$, até agora existentes na Bacia do São Francisco, mostram ampla correlação regional com padrões isotópicos dissociados de mudanças litológicas e de ambientes deposicionais. Por isso podem ser interpretados

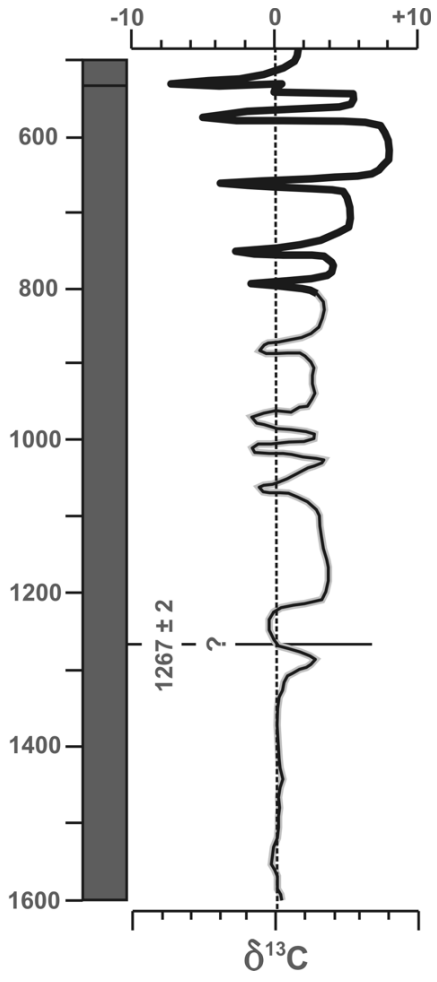

Figura 4 - Curva isotópica generalizada para o carbono do Meso ao Neoproterozóico (modificado de Kah et al. 1998).

como variações seculares do reservatório marinho de carbono e, tentativamente, comparados à curva isotópica global da figura 4.

Os carbonatos da Megasseqüência Paranoá (Serra de São Domingos) apresentam valores compatíveis com o intervalo basal do Mesoproterozóico de 1600 a $1300 \mathrm{Ma}$, enquanto os carbonatos da base da Megasseqüência São Francisco (na seção apresentada) apresentam boa correlação a partir das primeiras excursões negativas do Neoproterozóico, isto é, a partir de 1000 Ma. Uma vez que valores fortemente positivos de $\delta^{13} \mathrm{C}$ só começam a prevalecer ao final do Neoproterozóico (a partir de $700 \mathrm{Ma}$ ), fica novamente assinalada a discordância entre os carbonatos da base e topo da Megasseqüência São Francisco.

As excursões negativas de alta amplitude, observadas na figura 4 e nos carbonatos basais da Megasseqüência São Francisco, coincidem com unidades carbonáticas transgressivas que capeiam depósitos glaciais e, comumente, são excelentes ferramentas de correlação regional. Entre os períodos glaciais, os carbonatos são fortemente enriquecidos em $\delta^{13} \mathrm{C}$. Essas variações isotópicas bruscas são reflexos de mudanças: (1) na produtividade biológica na superfície dos oceanos, (2) na composição isotópica dos reservatórios de carbono, (3) no padrão de circulação vertical dos oceanos, (4) no fracionamento isotópico relacionado com a concentração do íon carbonático e (5) no fracionamento orgânico 
sobre a taxa de soterramento do carbono total. Todos esses fatores estão vinculados a variações climáticas globais (Hoffman et al. 1998).

Essa dicotomia paleoclimática (associação de diamictitos glaciais com carbonatos típicos de águas quentes) é considerada ainda um enigma na história do Neoproterozóico. Entre as várias hipóteses apontadas por Hoffman et al. (1998), pode-se citar a redução da luminosidade solar, a alta obliqüidade orbital, o rebaixamento do nível de $\mathrm{CO}_{2}$, a migração dos pólos, o aumento rápido do efeito albedo, a reinterpretação dos diamictitos como derivados de megaimpactos e os oceanos estagnados.

MEGASSEQÜÊNCIA SÃO FRANCISCO Segundo o modelo paleogeográfico proposto por Martins (1999), a Megasseqüência São Francisco teria se depositado a princípio sobre uma topografia irregular, que evoluiu para uma rampa carbonática distalmente escarpada e posteriormente para uma sucessão de rampas homoclinais empilhadas (Fig. 5).

Os comportamentos das superfícies de correlação abaixo e acima do datum na figura 5 são bem distintos, individualizando dois momentos deposicionais diferentes. A princípio, a bacia carbonática teve sua morfologia controlada pelo substrato, podendo ter um padrão homoclinal, onde as fácies carbonáticas de água rasa passam gradualmente para água profunda e depois para sedimentos baciais ou distalmente escarpados. Posteriormente, esse sistema evoluiu para uma sucessão de rampas empilhadas verticalmente (ramp stack).

Como em todas as plataformas carbonáticas, a unidade básica de construção de uma rampa são os ciclos deposicionais de rasamento ou paraseqüências de pequena escala. Com exceção das rampas distalmente escarpadas, a sua espessura final raramente irá ultrapassar 200 metros, refletindo o pouco espaço de acomodação disponível (Wright \& Burchette 1996). Como um mecanismo de defesa, as taxas de produção sedimentar também não serão muito altas. Em geral, as sucessões carbonáticas em uma rampa mostram uma acreção vertical e lateral cumulativa, por meio de um processo repetitivo de afogamento, recuperação e progradação em resposta a uma subida relativa do nível do mar de $2^{\mathrm{a}}$ ou $3^{\mathrm{a}}$ ordem. Esse é o processo que irá gerar as sucessões empilhadas verticalmente ou ramp stack.

As superfícies de afogamento são facilmente identificáveis pela variação brusca de fácies de carbonatos proximais para fácies de rampa externa (mudstones terrígenos, lamas carbonáticas argilosas ou ritmitos), que se tornam mais rasa em direção ao topo, até a unidade seguinte, mais proximal (Wright \& Burchette 1996).

O mais crítico nos modelos de rampas carbonáticas é a identificação em rampas homoclinais dos tratos de mar baixo. Devido ao ângulo de mergulho muito baixo das rampas, se a queda relativa do nível do mar for pequena ( $4^{\mathrm{a}}$ ou $5^{\mathrm{a}}$ ordem), serão muito poucas as variações sedimentares entre o trato de sistema de mar alto e o trato de mar baixo subseqüente. Apenas a presença de feições de exposição poderá assinalar o limite entre os dois tratos.

Quando a queda do nível do mar ultrapassa o nível base de ondas normais ( $3^{\mathrm{a}}$ ordem), os sedimentos de rampa interna do trato de mar baixo irão ficar completamente dissociados do trato de mar alto anterior. Uma queda do nível do mar dessa ordem pode expor e carstificar a rampa interna, e sedimentos fluviais podem cortar a área exposta e se acumular mais distalmente (Burchette \& Wright 1992). Baseado nesse modelo, os depósitos da Megasseqüência São Francisco foram divididos em no mínimo quatro seqüências deposicionais distintas, a saber, (Fig. 6):

Seqüência 1 A Seqüência 1 corresponde aos depósitos glaciogênicos da Formação Jequitaí, que foram aqui separados pela natureza dos processos a eles relacionados, muito distintos das seqüências posteriores. Sismicamente não se observa nenhuma discordância entre essa unidade e as sobrejacentes, e sim uma concordância relativa, mas o recobrimento sísmico ficou limitado às porções baciais da bacia, principalmente para esse tempo (Fig. 1).

$\mathrm{Na}$ borda noroeste, onde foram descritas as seções de superfície, o limite entre essa seqüência e a Megasseqüência Paranoá é erosivo e expõe diferentes níveis da seqüência subjacente. Tal fato sugere que essa região era topograficamente mais elevada, do que a área onde existe recobrimento sísmico, provavelmente uma região plataformal.

Na serra da Água Fria, os pavimentos estriados imediatamente abaixo desses depósitos e a distribuição de diamictitos maciços entre diamictitos estratificados e amalgamados na base dessa seqüência indicam a existência de outro alto topográfico a leste. Esses depósitos provavelmente pertencem a um trato de sistema diverso dos observados em subsuperfície (Figs. 5 e 6 ).

Não é simples a interpretação, do ponto de vista climático, dos diamictitos das seqüências glaciais antigas em termos de avanço e retração dos ciclos de gelo, porque são muitos os fatores que controlam a acumulação e preservação dessas litofácies nas bacias marinhas (Eyles et al. 1985). Durante o nível de mar baixo, ocorre erosão, seguida de deposição subglacial. Gelo proximal, seguido de gelo distal e sedimento marinho ocorre durante a subida glácio-eustática do nível do mar. O rebote gerado pela compensação isostática pósglacial tenderá também a ser erodido. Assim, unidades diamictíticas resultantes de retrabalhamento podem ser geradas durante vários momentos da história de sedimentação de uma bacia (Miller 1996).

Neste trabalho não foi realizado um estudo detalhado das associações glaciogênicas e seus limites de seqüência, de forma a determinar as variações do nível do mar, à medida que a capa de gelo declina e aumenta. Entretanto, a presença dessas associações de fácies preferencialmente junto à paleodepressões, associadas aos eventos de ressedimentação por fluxos gravitacionais pode ser interpretada como um trato de sistema de mar alto durante um período de deglaciação. Mas pode também corresponder à parte de uma cunha do 


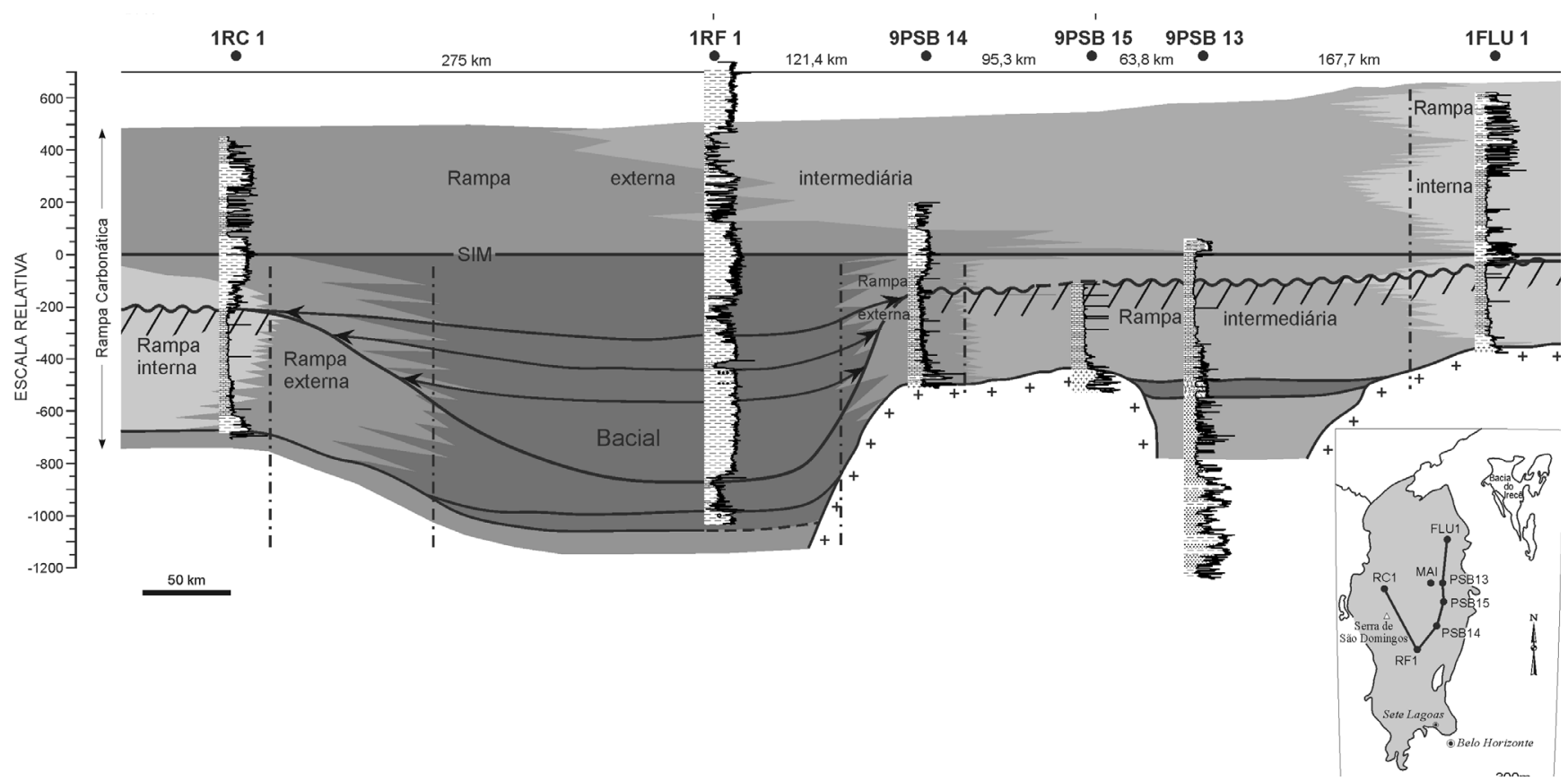

Figura 5 - Seção paleogeográfica esquemática com as principais subdivisões ambientais. $O$ datum de referência são os folhelhos mais radioativos da seqüência transgressiva (Formação Serra de Santa Helena), acima das unidades carbonáticas basais da cobertura cratônica.

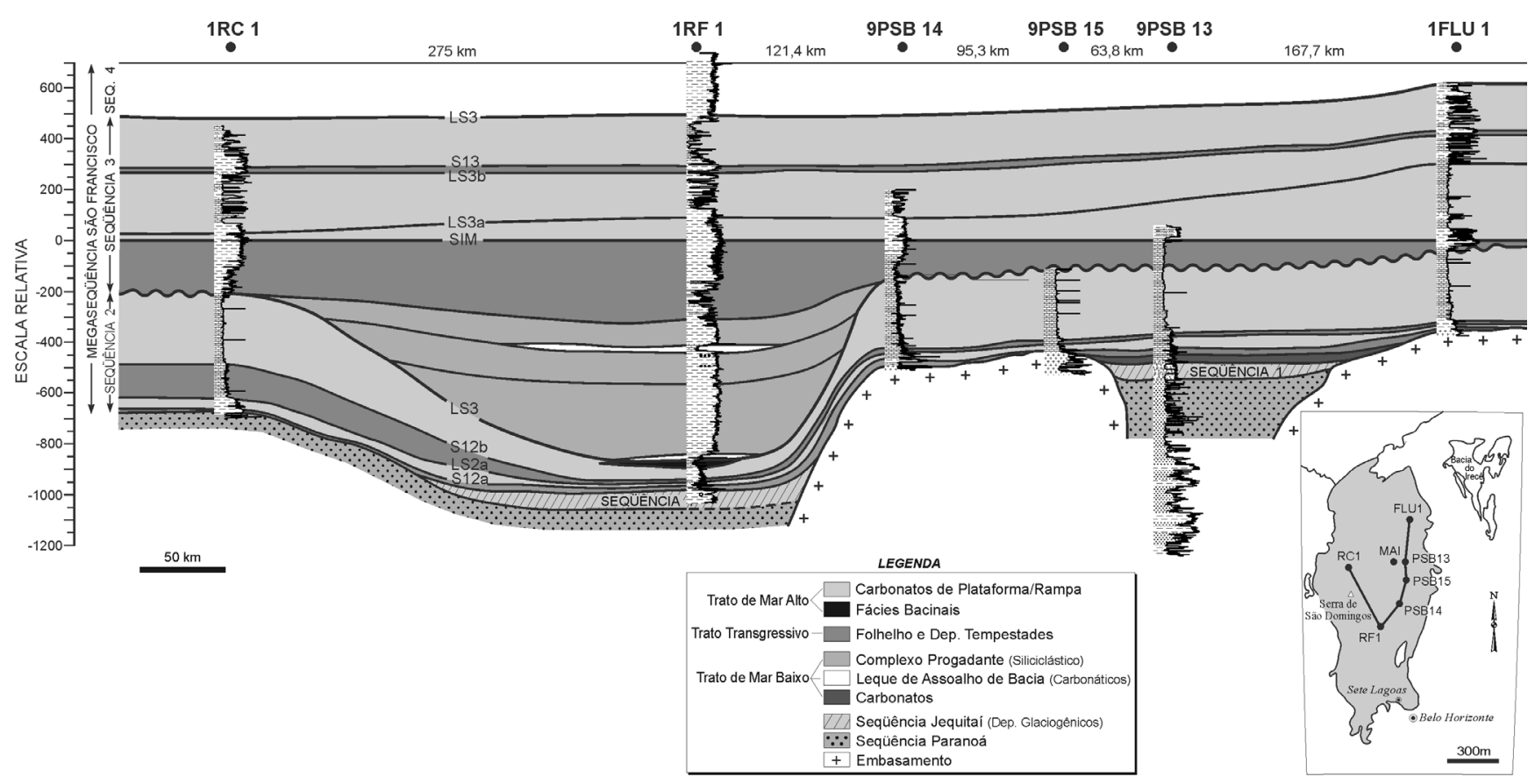

Figura 6 - Seção esquemática da Megasseqüência São Francisco, baseada em dados de subsuperfície mostrando as seqüencias e os tratos de sistemas reconhecidos.

trato de sistema de mar baixo, resultado da erosão do rebote isostático pós-glacial. Em ambas as alternativas, os diamictitos amostrados não estariam registrando um evento glacial, mas a erosão e retrabalhamento de seus sedimentos (Fig. 7.1).

Seqüência 2 A seqüência 2 abrange litoestratigraficamente os carbonatos da base da Formação Sete Lagoas até seu terço superior. Apresenta uma tendência progradacional bem marcada, muito clara em perfil e no empilhamento faciológico, podendo ser dividida em dois ciclos deposicionais de maior ordem (S2a e S2b), separados por um limite de seqüência (LS2a) inferido a partir da brusca variação no padrão faciológico e de perfis. O trato de sistema de mar baixo só pode ser observado nas porções baciais e nas áreas deprimidas dos paleoaltos, como corpos de carbonatos maciços intercalados a folhelhos resultantes de fluxos gravitacionais ou 
(1) SEQÜÊNCIA 1

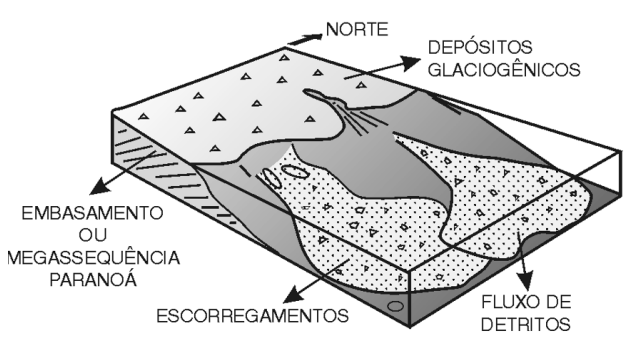

(3) SEQÜÊNCIA 3 TRATO DE SISTEMA DE MAR BAIXO

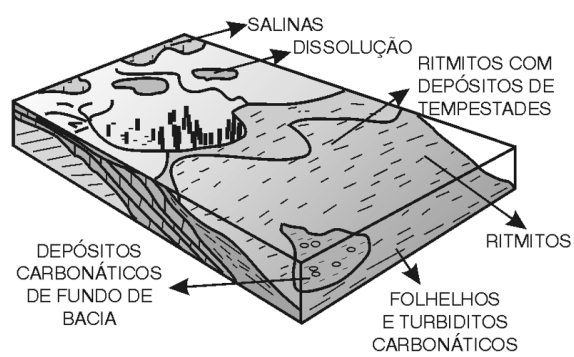

(5) SEQÜÊNCIA 3 TRATO DE SISTEMA DE MAR ALTO

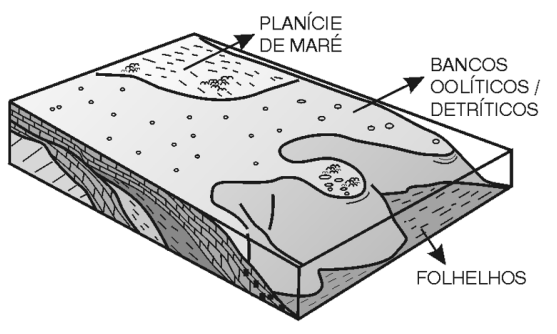

(2) SEQÜÊNCIA 2

TRATO DE SISTEMA DE MAR ALTO

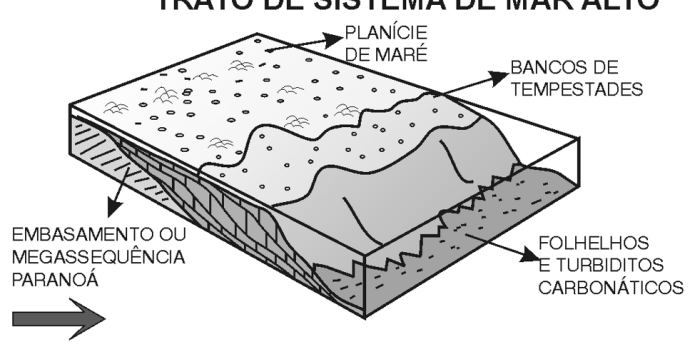

(4) SEQÜÊNCIA 3 TRATO DE SISTEMA TRANSGRESSIVO

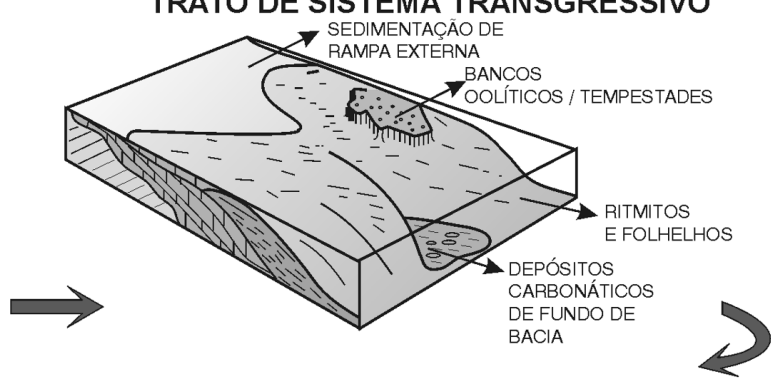

(6) SEQÜÊNCIA 4

TRATO DE SISTEMA DE MAR ALTO

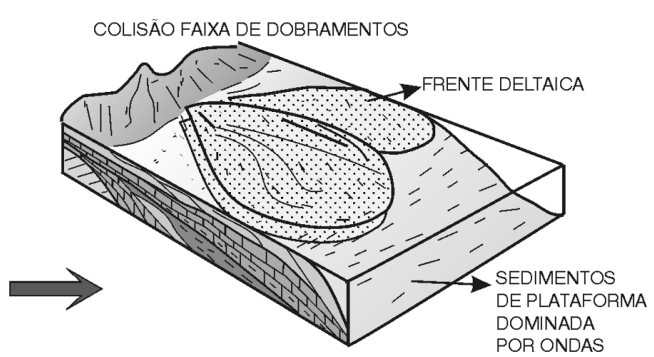

MODELO DEPOSICIONAL PARA A MEGASSEQÜÊNCIA SÃO FRANCISCO

Figura 7 - Modelo deposicional para a Megasseqüência São Francisco.

fluxo de detritos (Figs. 6 e 7.2).

Os dolomitos, que recobrem abruptamente os diamictitos glaciogênicos, estariam associados ao início do trato de sistema transgressivo. Essa justaposição carbonato dolomítico-diamictito é encontrada em muitas sucessões glaciomarinhas neoproterozóicas, como no Grupo Otavi, Cráton do Congo, na Namíbia (Hoffman et al. 1998), na Formação Egan, na região de Kimberley, Austrália (Corkeron 1998) e na plataforma carbonática neoproterozóica Krol, Índia (Kaufman et al. 1998). Se essa capa carbonática fosse típica de águas quentes, implicaria numa troca climática abrupta. Entretanto, os dados isotópicos de $\delta^{13} \mathrm{C}$ indicam águas mais doces, que podem estar associadas a uma deglaciação e, portanto, a águas mais frias. A deposição desses dolomitos teria ocorrido durante o período de deglaciação e subida do nível do mar, quando o aporte de terrígenos é reduzido, ou estaria associada à existência de fluxos carbonáticos detríticos dentro dos depósitos glaciais (Miller 1996), o que não parece ser o caso.

Os tratos de sistema transgressivos são caracterizados, em perfil, pelo caráter retrogradacional de suas fácies, que reflete um gradual aumento da lâmina d'água. Na ausência de outras feições diagnósticas, as superfícies de inundação máxima (SI2a e SI2b) foram assinaladas considerando o intervalo com leituras radioativas mais altas nos perfis de raios gama (Fig. 6).

Os tratos de sistema de mar alto constituem quase $80 \%$ de o registro sedimentar das rampas interna, intermediária e externa nessa seqüência (Figs. 5 e 6). A deposição da seqüência $\mathrm{S} 2 \mathrm{~b}$ (superior) parece ter sido o clímax da deposição carbonática, com uma sucessão progradante de fácies, quase sem aporte de terrígenos (Figs. 5 e 6). Nas áreas de rampa interna, os depósitos possuem uma assinatura gama uniforme, com valores cada vez mais baixos em direção ao topo, devido à presença de construções microbiálicas (estromatólitos).

O reconhecimento de uma superfície de exposição subaérea junto à rampa interna, associada a uma extensa dolomitização, brusca variação faciológica e forte quebra isotópica de amplitude regional nos valores de $\delta^{13} \mathrm{C}$, ajudou a estabelecer o limite (LS2) entre as seqüências 2 e 3 . Com exceção da porção bacial da bacia (onde só ocorre a quebra isotópica), a justaposição 
desses critérios pode ser considerada regional.

A dolomitização é interpretada como tendo ocorrido tanto durante a deposição, quanto na exposição subaérea dessa seqüência, no período de rebaixamento do nível do mar. O topo de sua ocorrência coincide com o salto isotópico positivo nos valores de $\delta^{13} \mathrm{C}$ em quase $5,0 \%$, fato interpretado como um evento isotópico regional de $1^{\text {a }}$ ou $2^{\mathrm{a}}$ ordem. Os dolomitos mesocristalinos da rampa interna são mais enriquecidos em $\delta^{13} \mathrm{C}$, se comparados aos dolomitos das rampas externa e intermediária. Isto sugere uma água do mar com temperatura de evaporação e salinidade altas (Mutti \& Simo 1994) e coincide com o aumento de restrição apontado pelos dados isotópicos para essas áreas.

Seqüiência 3 Litoestratigraficamente abrange todo o registro sedimentar do topo da Formação Sete Lagoas até o topo da Formação Lagoa do Jacaré. Começa com um trato de sistema de mar baixo preservado como um complexo progradante siliciclástico-carbonático, associado aos depósitos gravitacionais carbonáticos de fundo de bacia e restrito às suas porções baciais. A presença dessa feição é mais condizente com uma fisiografia de rampa distalmente escarpada, pois o mergulho muito baixo das rampas homoclinais não é propício ao desenvolvimento de depósitos desse tipo de associação (Figs. 5, 6 e 7.3).

Os complexos progradantes de mar baixo possuem uma natureza mais autóctone que os leques de assoalho de bacia e outros depósitos gravitacionais. A progradação geralmente ocorre na margem da plataforma ou rampa, à medida que os sedimentos marinhos avançam em direção as áreas mais rasas por sobre a topografia preexistente (Jacquin et al. 1991).

$\mathrm{O}$ trato de sistema transgressivo mostra um padrão de empilhamento retrogradante, que reflete o gradual afogamento do sistema. Nas rampas externas e intermediárias, esse trato é representado por uma série de sedimentos de alta energia, tipo bancos e barras oolíticas/oncolíticas, praias e depósitos de tempestades, que recobrem as fácies de água mais rasa da seqüência anterior. A linha de praia avançou fortemente em direção ao continente, de forma a permitir que a quase totalidade da bacia fosse capeada por um espesso pacote de folhelhos (Fig. 7.4). É nesse intervalo que foi posicionada a superfície de inundação máxima (SIM) da Megasseqüência São Francisco (Figs. 5 e 6), que coincide com o pico deposicional da Formação Serra de Santa Helena. Nos perfis de raios gama, o trato de sistema transgressivo exibe padrão bem serrilhado de alta freqüência, indicando tratar-se de seção muito condensada, com baixa taxa de sedimentação.

A partir desse momento criou-se um grande espaço de acomodação, com um mergulho muito mais suave que na seqüência anterior. $\mathrm{O}$ trato de sistema de mar alto seguinte exibe um padrão agradacional, empilhado, com uma sucessão em maior freqüência de fácies de mar alto e transgressivas empilhadas verticalmente. Nas rampas empilhadas, a acreção vertical cumulativa é uma resposta a uma lenta e longa subida relativa do nível do mar pontuada por pequenos rebaixamentos, que geram depósitos acamadados, com uma série de geometrias progradacionais e retrogradacionais sutilmente comprimidas (Burchette \& Wright 1992).

$\mathrm{Na}$ figura 6, a seqüência 3 foi subdivida a partir do trato de sistema de mar alto em três seqüências de mais alta freqüência, predominantemente agradacionais, de forma a ilustrar o empilhamento vertical dessas sucessões. Em todas as três, os limites de seqüência coincidem com uma superfície transgressiva. Na área do poço 1-FLU-1 (rampa interna), por exemplo, o limite da seqüência inferior (LS3a) é marcado por uma súbita variação faciológica, de fácies proximal de planície de maré para fácies de afogamento. O substancial desenvolvimento de depósitos de rampa externo-intermediária por toda a bacia (Fig. 7.5) e a presença de um sistema deposicional de rampa interna apenas a nordeste (na região do 1-FLU-1) sugerem a existência de uma rampa/plataforma mais permanente nessa área.

Um evento transgressivo de ordem maior recobre abruptamente o limite de seqüência seguinte (LS3b), uma superfície transgressiva, e atinge com menor expressão grande parte da bacia. O último trato de sistema de mar alto mostra um caráter progradacional, bem exemplificado nos poços 1-RC-1 e 1-RF-1.

Durante a formação dessa última seqüência completa, no trato de sistema de mar alto, o influxo de material siliciclástico na rampa não foi suficiente para cessar a produção carbonática. À medida que o influxo de terrígenos foi aumentando e que o espaço de acomodação foi diminuindo, os sistemas de rampa externa e intermediária foram sendo forçados a migrar lateralmente em direção à bacia, até o domínio total da sedimentação siliciclástica da próxima seqüência. $\mathrm{O}$ depocentro da rampa, embora geralmente confinado à parte central da bacia, deve ter variado lateralmente de seqüência para seqüência.

Os termos litoestratigráficos associados a esse trato de sistema de mar alto englobam os folhelhos da Formação Serra de Santa Helena a partir da SIM até os carbonatos do topo da Formação Lagoa do Jacaré.

O limite de seqüência LS3 foi estabelecido a partir da súbita mudança no padrão deposicional, que passa de associações de fácies carbonáticas de rampa intermediária para associações de fácies siliciclástica baciais. Apenas o poço 1-RF-1 amostrou essa passagem, e como seu posicionamento é praticamente bacial, não foram observadas evidências de exposição e truncamentos erosivos (Fig. 5). Também foram poucos e pobres os afloramentos que amostraram esse limite, o que dificulta o seu traçado.

Seqüência 4 Essa seqüência não dispõe de boa amostragem em subsuperfície. Suas associações de fácies siliciclástica de muito baixa energia, com raras estruturas associadas a ondas ou correntes, são típicas dos ambientes plataformais distais e baciais (Fig. 5, poço 1-RF-1). Numa análise preliminar será considerada como a parte distal de uma seqüência progradante de terrígenos marinhos de plataforma dominada por tempestades (Fig. 7.6), que culmina com a chegada do sistema flúvio-deltáico da Formação Três Marias (Chiavegatto 1992). 
DISCUSSÃO: A EVOLUÇÃO DEPOSICIONAL Um diagrama tempo versus espaço foi tentativamente construído a partir dos resultados apresentados anteriormente, e integrados aos trabalhos já realizados na bacia para ajudar a ilustrar a evolução deposicional da bacia durante o Meso/Neoproterozóico (Fig. 8). Três períodos distintos de sedimentação separados por discordâncias foram reconhecidos:

(1) Seqüência glaciogênica seguida de uma rampa carbonática distalmente escarpada, de idade Criogeniana, bem desenvolvida nas áreas norte/nordeste e sul, em bacia tectonicamente estável (seqüências 1 e 2 da Megasseqüência São Francisco respectivamente);

(2) Rampas homoclinais empilhadas verticalmente com sedimentação carbonática/siliciclástica, de idade Criogeniana, em bacia progressivamente afetada por eventos compressivos vindos da borda oeste (seqüência 3 da Megasseqüência São Francisco), e

(3) Plataforma rasa com sedimentação dominantemente siliciclástica, em bacia do tipo foreland, com menor expressão regional de idade Ediacarana inferior (seqüência 4 da Megasseqüência São Francisco).

A Megasseqüência Paranoá reflete uma deposição em uma bacia com uma taxa de subsidência baixa, que tem idade estimada entre 1350-950 Ma (Faria 1995). O limite entre as megasseqüências Paranoá e São Francisco representa uma grande queda relativa do nível do mar, com exposição subaérea e erosão dos sedimentos plataformais. Quando se deu essa passagem? Embora seja essa uma questão polêmica, a análise dos dados isotópicos de $\delta^{13} \mathrm{C}$ pode ajudar a situar quando esse evento ocorreu a situar melhor esse evento no tempo, a saber:

(i) a correlação dos valores de $\delta^{13} \mathrm{C}$ dos carbonatos do topo da Megasseqüência Paranoá e a curva de variação isotópica global permite estimar um limite máximo de deposição para esses carbonatos em torno de 1250 Ma (Fig. 4);

(ii) o comportamento muito negativo dos valores de $\delta^{13} \mathrm{C}$ dos carbonatos da base da Megasseqüência São Francisco (em torno de -5,0\%) indicam uma deposição sob condições marinhas pós-glaciais;

(iii) na curva de variação isotópica global de $\delta^{13} \mathrm{C}$, as primeiras incursões negativas breves só começam a ocorrer a partir de 1000 Ma e ocorrem pontuadamente até $800 \mathrm{Ma}$ (Figs. 4 e 9). A partir de $800 \mathrm{Ma}$, as incursões negativas começam a atingir valores em torno de $-5,0 \%$, semelhantes aos encontrados nos carbonatos basais da Megasseqüência São Francisco;

(iv) essas incursões negativas coincidem com no mínimo quatro idades glaciais no Neoproterozóico, indicadas por triângulos na figura 9 (Kaufman 1998), e

(v) os depósitos carbonáticos, sobrejacentes aos carbonatos basais isotopicamente negativos, apresentam valores $\delta^{13} \mathrm{C}$ muito fracamente positivos, só correlacionáveis aos valores da base da curva global de Kaufman (1998).

Sendo assim, um grande hiato deposicional parece separar as duas megasseqüências, sendo possível que a glaciação Jequitaí tenha ocorrido em torno de $800 \mathrm{Ma}$. Um intenso processo erosivo expõe diferentes níveis deposicionais da Megasseqüência Paranoá, desenvolvendo uma discordância regional significativa. Durante a subida relativa do nível do mar, resultante da "deglaciação Jequitaí", os depósitos glaciogênicos da plataforma externa foram retrabalhados, gerando depósitos por fluxos gravitacionais e escorregamentos, que são conduzidos às áreas deprimidas ou baciais (seqüência 1 da Megasseqüência São Francisco).

A paleogeografia da bacia já apresenta uma fisiografia de rampa distalmente escarpada e as mudanças climáticas e no aporte de terrígenos criaram condições para a instalação de uma fábrica carbonática prolífera em atividade microbial nas rampas internas e intermediárias (seqüência 2 da Megasseqüência São Francisco). Os valores isotópicos de $\delta^{13} \mathrm{C}$ sugerem um progressivo aumento nas condições de restrição e temperatura na bacia, à medida que esse sistema carbonático prograda, principalmente na direção nordeste (Fig. 3). Para oeste a situação de aparente equilíbrio isotópico indica condições de maior ventilação (mares mais abertos).

Uma queda relativa do nível do mar culmina com a exposição subaérea, dolomitização e erosão das rampas interna e intermediária, principalmente nas áreas nordeste, sul e noroeste, e a formação de um complexo progradante de mar baixo no depocentro da bacia, marcando o início da seqüência 3. Essa discordância coincide com um salto isotópico positivo, em quase $5,0 \%$ nos valores de $\delta^{13} \mathrm{C}$, de expressão regional, possivelmente associado a um evento global de $1^{\text {a }}$ ou $2^{\text {a }}$ ordem. Nas curvas isotópicas globais de Kah et al. (1998) e Kaufman (1998), figuras 4 e 9 respectivamente, valores dessa ordem ocorrem entre 600 e $680 \mathrm{Ma}$, deixando um hiato deposicional entre as seqüências $2 \mathrm{e}$ 3 de aproximadamente 20Ma.

$\mathrm{O}$ evento transgressivo subseqüente cobriu quase toda a área cratônica, com uma extensa sedimentação de rampa distal. Apenas na área nordeste, esse afogamento possui menos expressão. A partir desse momento, o espaço de acomodação da bacia já é bem maior, e seu preenchimento pode ser caracterizado como de uma rampa homoclinal empilhada (ramp stack), aonde pulsativamente chegam terrígenos muito finos.

Na seqüência 3, a bacia é completamente diferente: a fisiografia é outra, o mar está isotopicamente enriquecido em ${ }^{13} \mathrm{C}$, os terrígenos competem diretamente com os carbonatos. Que evento teria condicionado essas mudanças? Para Guimarães \& Dardenne (1998), os termos terrígenos da Megasseqüência São Francisco, principalmente a partir da sua transgressão máxima, indicam que os sedimentos se acumularam em uma bacia já sob influência de processos colisionais. Isto explicaria as aparentes variações laterais no posicionamento do depocentro deposicional da bacia, durante o empilhamento dessa seqüência e o aspecto cíclico da seqüência 3 .

Os processos colisionais fazem parte do evento tectônico Brasiliano, que parece apresentar pelo menos dois picos deformacionais/metamórficos. O mais velho (750-790 Ma) é tradicionalmente correlacionado à colisão dos crátons Amazônico e São Francisco, e coinci- 


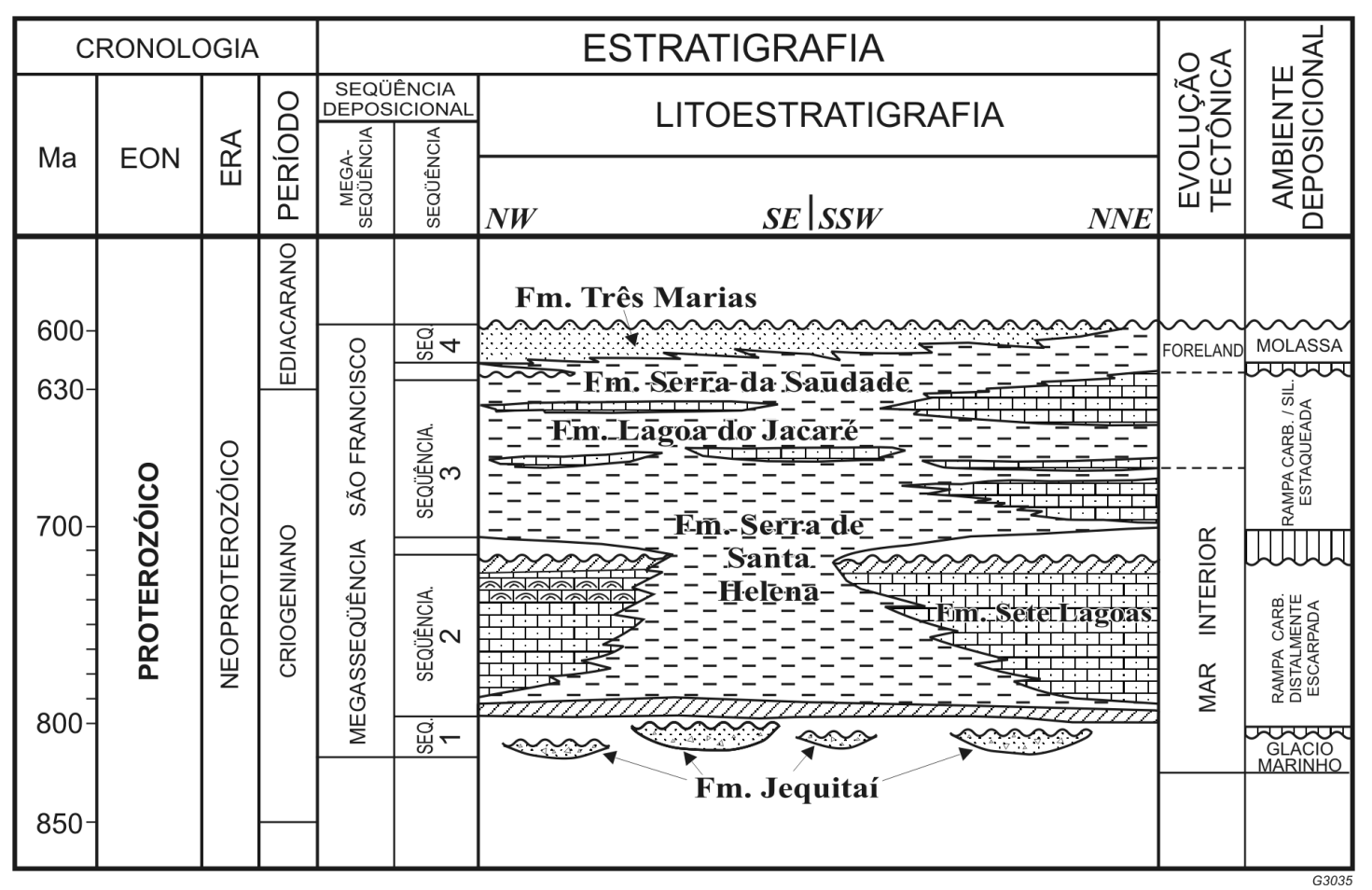

Figura. 8 - Diagrama tempo versus espaço para a Megasseqüência São Francisco.

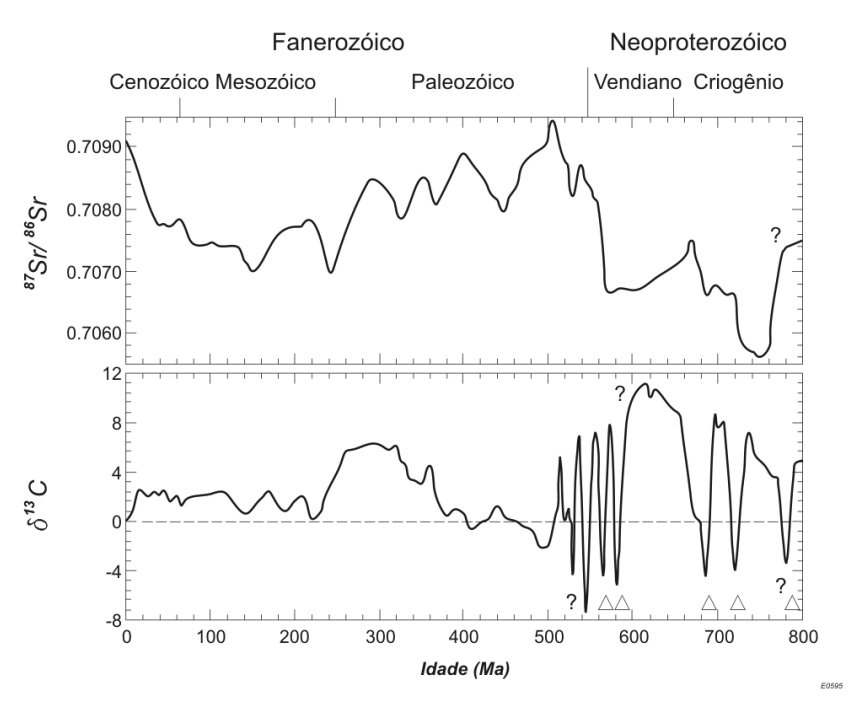

Figura 9 - Curva de variação global das composições isotópicas do carbono $\left(\delta^{13} \mathrm{C}\right)$ e estrôncio ${ }^{87} \mathrm{Sr}{ }^{86} \mathrm{Sr}$ dos carbonatos marinhos nos últimos $800 \mathrm{Ma}$. Observar que as variações fortemente negativas de $C$ coincidem com pelo menos quatro idades glaciais neoproterozóicas, assinaladas com triângulos (modificado de Kaufman 1998).

de com o início da deposição da Megasseqüência São Francisco. O mais novo (630-600Ma), pode estar relacionado à acreção de um bloco menor na margem oeste da faixa de dobramentos Brasília (Pimentel et al. 1998) e ser cronocorrelato à deposição da seqüência 4.

Do ponto de vista estratigráfico, o avanço das escamas de empurrão a oeste e o aumento do aporte de terrígenos interromperam definitivamente a sedimentação carbonática. A bacia passa a se comportar como uma bacia do tipo foreland em relação às faixas de dobramentos Brasília e Araçuaí (Alkimim et al. 1996). Apesar de não existir indicação alguma, o limite entre as seqüências 3 e 4 deve ter sido erosivo nas porções proximais da bacia que ficavam a oeste, mas estariam atualmente erodidos.

CONCLUSÃO Sistemas deposicionais carbonáticos e siliciclásticos coexistem lado a lado, mas sempre em escala regional e controlados pela variação eustática do nível do mar. Localmente a deposição é mutuamente excludente.

O refinamento da coluna estratigráfica do ponto de vista da Estratigrafia de Seqüências foi parcial, tendo sido reconhecidos três períodos distintos de sedimentação, separados por discordâncias. A Megasseqüência São Francisco foi dividida em quatro seqüências deposicionais, a saber: seqüência 1, glácio-marinha; seqüência 2 , carbonática progradacional em rampa distalmente escarpada; seqüência 3 , carbonática-siliciclástica em rampa homoclinal e seqüência 4, plataforma rasa progradacional dominantemente siliciclástica.

Essas seqüências estão separadas por discordâncias marcadas por descontinuidades faciológicas e fortes quebras isotópicas. Entre as seqüências 2 e 3, a quebra isotópica coincide com fácies típicas de exposição subaérea e níveis de dolomitização. $\mathrm{O}$ hiato entre essas seqüências foi estimado em $20 \mathrm{Ma}$, por correlação com a curva de variação estratigrafia isotópica global do $\delta^{13} \mathrm{C}$.

A estratigrafia isotópica mostra uma crescente 
restrição nas condições deposicionais da bacia, acentuada durante a deposição da Megasseqüência São Francisco.

Uma anomalia negativa de $\delta^{13} \mathrm{C}$, associada ao "evento glacial Jequitaí", marca o início da deposição dos carbonatos da seqüência 2, formando um horizonte isotópico contínuo, que pode ser usado para assinalar a discordância que separa as megasseqüências São Francisco e Paranoá em áreas onde as fácies glaciogênicas estiverem ausentes.

A recomposição paleogeográfica da bacia, ao tempo da seqüência 2 , mostra uma área progressivamente mais confinada a nordeste e mais ventilada a oeste. Esse contexto é subitamente modificado ao final da deposição desses carbonatos, quando novas condições paleogeográficas se estabeleceram na bacia, provavelmente associadas a um evento global de $1^{\mathrm{a}}$ ou $2^{\mathrm{a}}$ ordem.

\section{Referências}

Alkmin F.F., Chemale Jr.F. \& Endo I. 1996. A deformação das coberturas proterozóicas do Cráton do São Francisco e o seu significado tectônico. Rev. Esc. Minas, 49:22-38.

Burchette T.P. \& Wright V.P. 1992. Carbonate ramp depositional systems. Sed. Geol., 79:3-57.

Chiavegatto J.R.S. 1992. Análise estratigráfica das seqüências tempestiticas da Fm. Três Marias (Proterozóico Sup.), na porção meridional da Bacia do São Francisco. Dissertação de Mestrado, Universidade Federal de Ouro Preto, $196 \mathrm{p}$.

Corkeron M. 1998. Neoproterozoic glaciation in Kimberley region, Australia: sedimentology and depositional environments. In: International Sedimentological Congress, 15, Alicante, Abstracts, p. 272.

Dominguez J.M.L. 1993. As coberturas do Cráton do São Francisco: uma abordagem do ponto de vista da análise de bacia. In: J.M.L. Dominguez \& A. Misi (eds.) $O$ Cráton do São Francisco. Salvador. SBG. BA-SE/SGM/ CNPq, p. 137-159.

Eyles C.H., Eyles N. \& Miall A.D. 1985. Models of glaciomarine sedimentation and their applications to the interpretation of ancient glacial sequences. Palaeogeo., Palaeoclim., Palaeoeco., 51:15-84.

Faria A. 1995. Estratigrafia e sistemas deposicionais do Grupo Paranoá nas áreas de Cristalina, Distrito Federal e São João d'Aliança-Alto Paraíso de Goiás. Tese de Doutoramento, Universidade de Brasília, 198 p.

Guimarães E.M. \& Dardenne M.A. 1998. Características de coberturas cratônicas relacionadas com faixas de deformação: as bacias Paranoá e Bambuí e a evolução da Faixa Dobrada Brasília. In: SBG, Congr. Bras. Geol., 40, BH, Anais, p. 4.

Hoffman P.F., Kaufman A.J. \& Halverson G.P. 1998. Comings and goings of Global Glaciations on a Neoproterozoic Tropical Platform in Namibia. GSA Today, 8(5):1-9.

Irwin H. 1980. Early diagenetic carbonate precipitation and poor fluid migration in the Kimmeridge Clay of Dorset, England. Sedim. 27:577-591.

Iyer S.S., Babinski M., Krouse H.R. \& Chemale F.Jr. 1995. Highly ${ }^{13} \mathrm{C}$-enriched carbonate and organic matter in the Neoproterozoic sediments of the Bambuí Group, Brazil. Precambrian Res., 73:271-282.

Jacquin T., Arnaud-Vanneau A., Arnaud H., Ravenne C. \& Vail P.R. 1991. Systems tracts and depositional sequences in a carbonate setting: a study of continuous outcrops from platform to basin at the scale of seismic lines. Mar. Petroleum Geol., 8:122-139.
Kah L.C., Sherman A.B., Narbonne G.M., Knoll A.H. \& Kaufmam A.J. 1998. $\delta^{13} \mathrm{C}$ Isotope Stratigraphy of Proterozoic Bylot Supergroup, Northern Baffin Island: Implications for Regional Lithostratigraphic Correlations. In: AAPG, Annual Convection, Salt Lake City, Extended Abstracts, v.2, p. A-348.

Kaufman A.J. 1998. Neoproterozoic chemostratigraphy: key events in Earth history ordered by detailed intra- and inter-basinal correlation. In: SBG-MG, Congresso Brasileiro de Geologia, 40, Anais, p. 2.

Kaufman A.J., Jiang G. \& Christie-Blick N. 1998. Varanger Ice Ages in India Potencially revealed by Integrated Sequence and Carbon Isotope Stratigraphy. In: AAPG, Annual Convection, Salt Lake City, Extended Abstracts, v.2, p. A-354.

Li H.-C. \& Ku T.-L. 1997. $\delta^{13} \mathrm{C}-\delta^{18} \mathrm{O}$ covariance as a paleohydrological indicator for closed-basin lakes. Palaeogeo., Palaeoclim., Palaeoeco., 133:69-30.

Martins M. 1999. Análise estratigráfica das seqüências mesoproterozóicas (borda oeste) e neoproterozóicas da Bacia do São Francisco. Dissertação de Mestrado, Universidade Federal do Rio Grande do Sul, 214 p.

Miller J.M.G. 1996. Glacial sediments. In: H.G. Reading (ed.) Sedimentary Environments: Process, Facies and Stratigraphy. Third edition. Oxford: Blackwell Science Ltd.. p. 454-484.

Mutti M. \& Simo J.A. 1994. Distribution, petrography and geochemistry of early dolomite in ciclity shelf facies, Yates Formation (Guadalupian), Capitain Reef Complex, USA. In: B. Purser, M. Tucker \& D. Zenger (eds.) Dolomites: A volume in honour of Dolomieu. Special Publication no. 21. IAS. Oxford: Blackwell Science Publication, p. 91-107.

Pimentel M.M., Fuck R.A. \& Yunges S. 1998. New Sm-Nd Isotopic constraints for the age of metamorphic events in the neoproterozoic Brasília Belt, central Brazil. In: International Conference on Precambrian and craton Tectonics, 14, Abstracts, p. 50-52.

Wright V.P. \& Burchette T.P. 1996. Shallow-water carbonate environments. In: H.G. Reading (ed.) Sedimentary Environments: Process, Facies and Stratigraphy. 3 ed. Oxford: Blackwell Science Ltd., p. 325-394.

Manuscrito CSF-08

Submetido em 31 de maio de 2006 Aceito em 01 de março de 2007 